\title{
Experimental Characterization of A Piezoelectric Transducer Array Taking into Account Crosstalk Phenomenon
}

\author{
Abdelmajid Bybi ${ }^{1, *}$, Driss Khouili ${ }^{2}$, Christian Granger $^{3}$, Mohammed Garoum ${ }^{1}$, \\ Ahmed Mzerd ${ }^{4}$, Anne-Christine Hladky-Hennion ${ }^{3}$ \\ ${ }^{1}$ Mohammed V University in Rabat, High School of Technology in Sale, MEAT, Sale, Morocco \\ ${ }^{2}$ Mohammed V University in Rabat, High School of Technology in Sale, LASTIMI, Sale, Morocco \\ ${ }^{3}$ ISEN Department, IEMN, UMR CNRS 8520, Lille, France \\ ${ }^{4}$ Mohammed V University in Rabat, Faculty of Science, STCE, Energy Research Center, Rabat, Morocco \\ Received 29 May 2019; received in revised form 20 July 2019; accepted 06 August 2019 \\ DOI: https://doi.org/10.46604/ijeti.2020.4348
}

\begin{abstract}
Ultrasonic transducer arrays are generally composed of several piezoelectric elements arranged in 1D or 2D ways. Crosstalk is an undesirable phenomenon decreasing the performance of these devices. It generates parasitic displacements at the elements' radiating surfaces, which changes the directivity of the array. Furthermore, the transducer's displacement plays a critical role in terms of the focal area and transferred intensities. The objective of this paper is to characterize a piezoelectric array composed of seven-elements made of PZ 27 ceramic experimentally. It investigates the effects of the crosstalk phenomenon on the array's performance in particular. The results have shown that the array's elements vibrate mainly in thickness mode, but the displacement is not uniform along their length due to the contribution of a parasitic length mode. Moreover, the major parasitic displacements are obtained on the neighboring passive elements: about $-7.3 \mathrm{~dB},-11 \mathrm{~dB}$, and $-12 \mathrm{~dB}$, on the first, the second, and the third elements, respectively.
\end{abstract}

Keywords: ultrasonic transducer arrays, displacement measurement, directivity pattern, crosstalk

\section{Introduction}

Ultrasound array and phased array systems have been widely used in medical imaging applications, e.g. obstetrics, abdomen, ophthalmology and intravascular [1-3] and have already become the preferred imaging method in a variety of clinical situations. Thanks to its advantages, i.e. safety, low cost, portability, and high spatial resolution, this technique remains for more than 50 years, a promising technology compared to other ones (X-ray, Digital X-ray, and magnetic resonance imaging). The major purpose of the research in this area is the optimization of the transducer arrays' performance to obtain a high image resolution for more reliable and safe diagnostics. These efforts include the use of new materials, like single crystals (LiNbO3, PMN-PT, and PIMNT) [4-7] and piezo-composite materials for applications needing operating frequencies superior or equal to $30 \mathrm{MHz}$ [8-10]. Similarly, silicon micro-machined transducers such as CMUT transducer arrays have been developed to replace conventional piezo-ceramic arrays, and thus electronic devices could be integrated on the same substrate [11-14]. Several works also focus on the understanding and minimization of the crosstalk phenomenon, which creates artifacts and decreases the quality of the obtained images [15-18]. In this context, several approaches have been adopted. The first one

* Corresponding author. E-mail address: abdelmajid_bybi@hotmail.fr

Tel: +212-6-39668291; Fax: +212-5-37881564 
proposes improvements at the level of design and manufacture of the transducer arrays. It investigates the geometry and dimensions of the kerf filling material [19-20] particularly, the optimization of the front matching layers [21-23] and the improvement of the Printed Circuit Board (PCB) are utilized to connect the transducer array elements [24-25]. The second method is based on corrective electrical excitations applied to the array's elements to minimize the parasitic displacements and thus reducing crosstalk [26-29]. The last approach concerns specific treatments realized on the excitation and reception signals to minimize crosstalk $[17,30]$. Finally, to improve the sensitivity of the transducer arrays, several research works are dedicated to the minimization of the electrical impedance of the array's elements using multilayer technology [31-33]. In this situation, the elements are connected acoustically in series but electrically in parallel which leads to reduced electrical impedance.

In several medical applications, therapeutic ultrasounds are based on single transducer and transducer arrays [34-35] with higher powers and mostly lower frequencies. Therefore, the optimal displacement generated by these transducers will play a critical role in terms of the focal area and transferred intensities. The aim of this paper is to characterize a transducer array composed of seven piezoelectric elements made of a conventional PZ 27 ceramic experimentally. It also points out the presence of a parasitical length mode coupled to the desired thickness one and it studies its effects on the physical behavior of the array, i.e. structure vibration and its radiation in water. Furthermore, this research work investigates the influence of the crosstalk phenomenon on the electroacoustical performance of the fabricated transducer array. The first section of this paper describes the transducer arrays utilized in medical imaging and presents the fabricated prototype briefly. It is also dedicated to the presentation of the experimental setups utilized to perform electrical (electrical impedance and crosstalk) and mechanical measurements (displacement and directivity pattern). In the second section, electrical impedance, displacement, and directivity pattern measurements are carried out in the case of a single piezoelectric element (elementary slender bar). The last section is dedicated to the experimental characterization of the fabricated seven-element transducer array. In this context, electrical impedance, crosstalk and displacement measurements are realized on each element of the transducer array vibrating in the air. The array is then tested in water and directivity pattern measurements are obtained using a PVDF hydrophone.

\section{Piezoelectric Transducer Arrays for Medical Imaging Applications}

\subsection{Structure description}

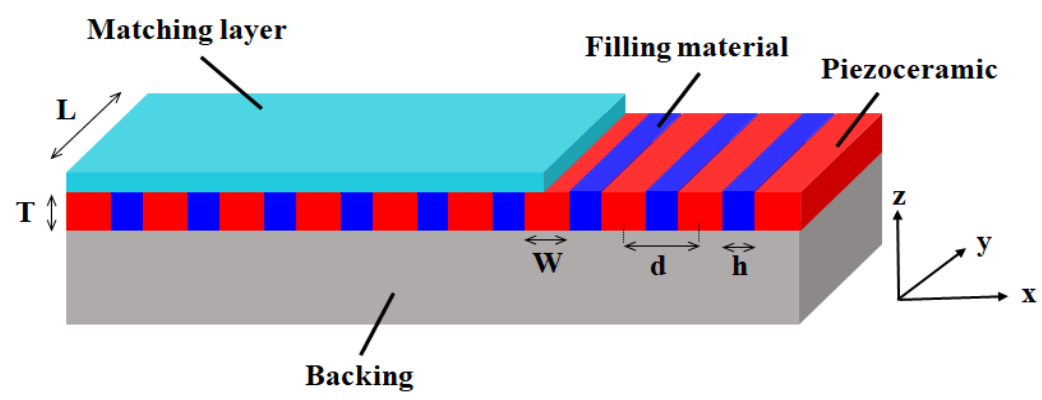

Fig. 1 Typical geometry of piezoelectric transducer array

Linear and phased transducer arrays utilized in medical imaging are generally composed of $\mathrm{N}$ piezoelectric elements having a thickness $\mathrm{T}$, a width $\mathrm{W}$ and a length $\mathrm{L}$, spaced by a distance $\mathrm{d}=\mathrm{W}+\mathrm{h}$ (d corresponds to the array's pitch and $\mathrm{h}$ is the filling material's width) and aligned as illustrated in Fig. 1. The elements are polarized in the thickness direction (z-axis) and are bonded to each other by a non-conductive resin. The thickness $\mathrm{T}$ depends on the desired operating frequency, which is approximately equal to a half of the wavelength in the piezoelectric material. To avoid the parasitic grating lobes, the width $\mathrm{W}$ must respect the Nyquist criterion $\mathrm{d}<\lambda_{\mathrm{w}} / 2\left(\lambda_{\mathrm{w}}\right.$ wavelength in the propagation medium: water in medical imaging) at the operating frequency.

To obtain a dominant thickness mode the ratio $\mathrm{W} / \mathrm{T}$ must be less than or equal to 0.5. Finally, the length $\mathrm{L}$ is usually taken much greater than $\mathrm{T}$ and $\mathrm{W}$ (approximately 10). The transducer array elements are also equipped with front and back 
matching layers to minimize the mismatching problem which creates a prolonged ringing after pulse excitation. Generally, the acoustic impedance of a conventional transducer is matched to one of the propagation media by one or two matching layers on its front face and a thick backing layer on its back face.

\subsection{Fabricated prototype and experimental setups}

(1) Seven-element transducer array

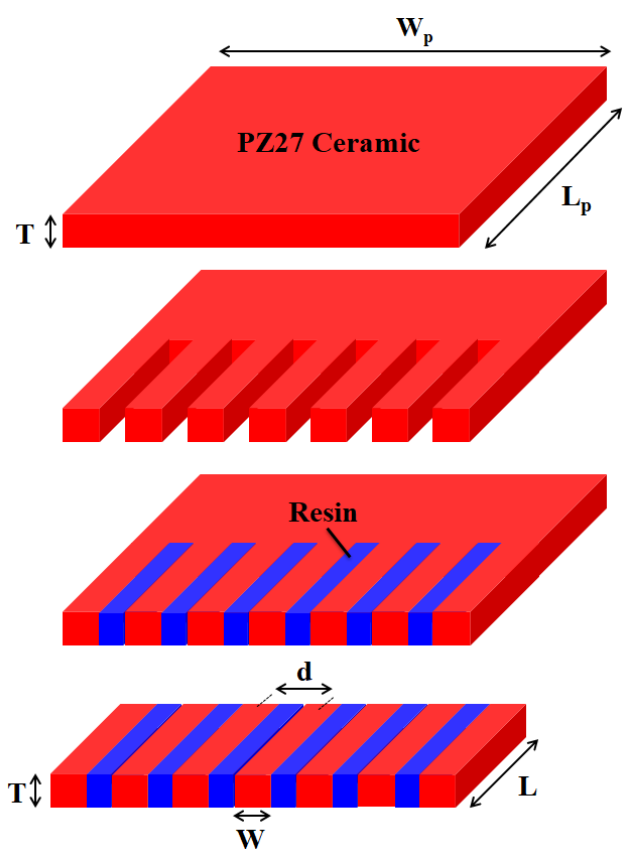

Fig. 2 Dice and fill technique

To fabricate easily our prototype, we opted for the classical dice and fill technique explained in Fig. 2. The procedure starts with a piezoelectric plate $\left(\mathrm{T}=3.3 \mathrm{~mm}, \mathrm{~W}_{\mathrm{p}}=7 \mathrm{~cm}\right.$ and $\mathrm{L}_{\mathrm{p}}=7 \mathrm{~cm}$ ) polarized in the thickness direction (Ferroperm, Kvistgaard, Denmark). The sample is then cut into elements using a diamond saw (Struers, Champigny Sur Marne, France) having a thickness $(\mathrm{a}=0.5 \mathrm{~mm})$ for a regular space between the elements $(\mathrm{d}=1.2 \mathrm{~mm})$ respecting the Nyquist criterion. The gap between the elements is then filled with a non-conductive resin PLEXCIL (ESCIL, Chassieu, France).

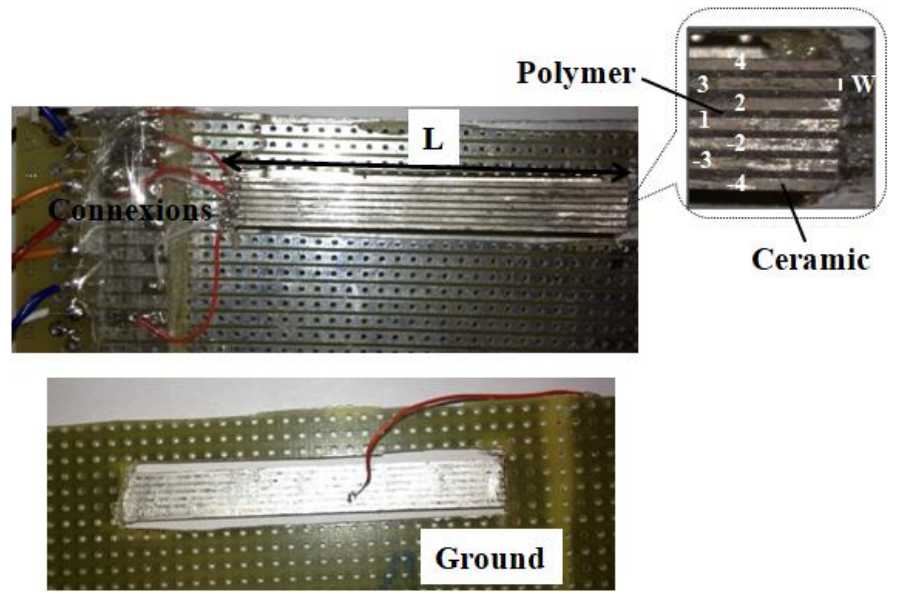

Fig. 3 The fabricated seven-element transducer array

This process is realized in vacuum conditions to minimize the presence of undesirable air bubbles between the elements. The structure is cut again to remove the undesirable ceramic parts. Finally, the transducer array obtained is mounted in the middle of a rigid Printed Circuit Board to facilitate the electrical connections and the manipulation of the prototype. Fig. 3 shows the manufactured transducer array (LMCPA, Maubeuge, France) composed of seven piezoelectric elements made of PZ27 Ferroperm ceramic having the following dimensions: $\mathrm{T}=3.3 \mathrm{~mm}, \mathrm{~W}=0.7 \mathrm{~mm}, \mathrm{~L}=37 \mathrm{~mm}$ and $\mathrm{d}=1.2 \mathrm{~mm}$. 
In our case, the fabricated transducer array is only composed of piezoelectric elements bonded to each other by a non-conductive acrylic resin, PLEXCIL (ESCIL, Chassieu, France). The matching layers are not taken into account to facilitate the fabrication of the prototype. This kind of transducer arrays is manufactured at the beginning to study particularly the mechanical crosstalk due to the filling material and the acoustical crosstalk caused by water. This would make testing our crosstalk correction methods easier [26]. To study the electroacoustical behavior of the fabricated prototype, electrical and mechanical measurements are realized on both single element slender bar (elementary transducer) and transducer array using different experimental setups.

\section{(2) Displacement measurements}

The displacement at the surface of the transducers (single element and transducer array) is measured using the experimental setup shown in Fig. 4. The latter is composed of low-frequency generators (Agilent 33250A) utilized to excite the single element / array elements. Displacement at different points is achieved using a Polytech psv400 Laser Vibrometer (Polytec, Châtillon, France) automatically controlled by a computer. The computer is also used for the acquisition of the experimental signals and to obtain the displacement profile.

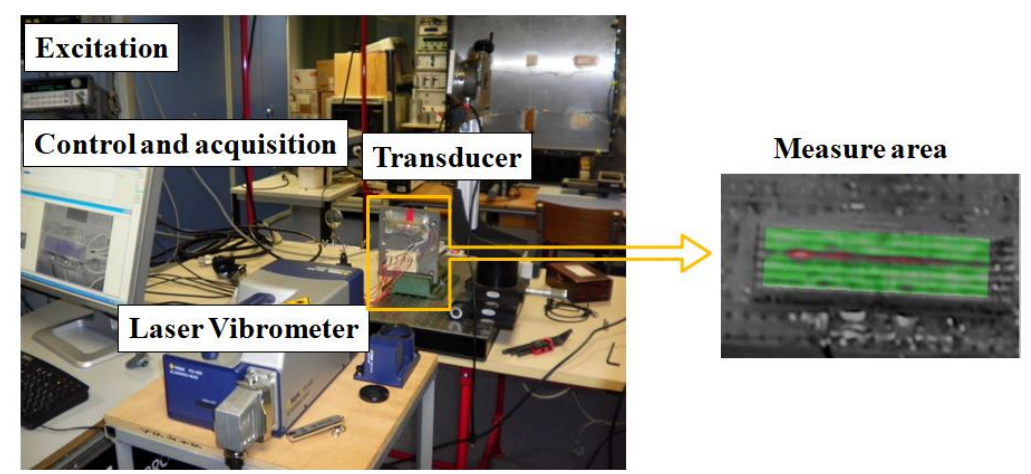

Fig. 4 Displacement measurement set-up

(3) Electrical impedance and crosstalk measurements

The electrical impedance measurements are realized on both transducers, i.e. single element and transducer array using an impedance analyzer WK Wayne Kerr 6540A (Wayne Kerr Electronics, West Sussex, UK). Crosstalk measurements are performed on the transducer array using the experimental set-up shown in Fig. 5. In this case, the central element " 1 " is excited by a Burst Generator (Agilent 33250A) delivering an electrical signal V1. The neighboring elements “2”, “-2”, “3”, “-3”, “4” and "-4" are connected individually to a digital oscilloscope displaying the parasitic signal generated on each element $(\mathrm{Vi}, \mathrm{i}=$ $2,-2,3,-3,4,-4)$.

The crosstalk level $\mathrm{C}(\mathrm{dB})$ is then deduced using the relation (1).

$$
\mathrm{C}(\mathrm{dB})=20 \log \left(\frac{\mathrm{Vi}}{\mathrm{V} 1}\right)
$$

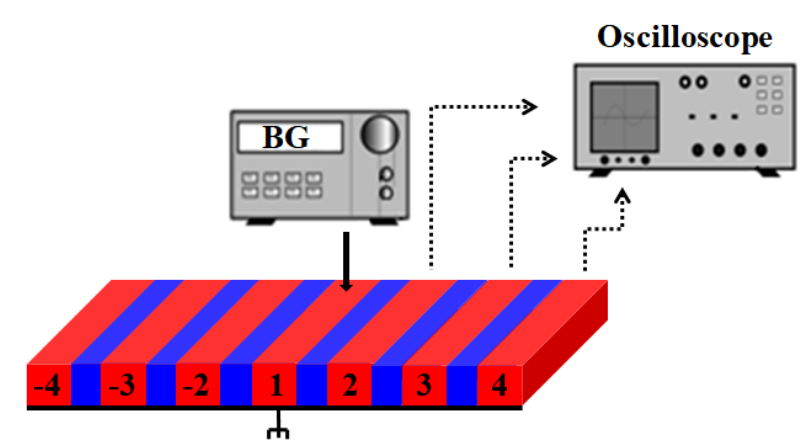

Fig. 5 Schematic description of the crosstalk measurement 
(4) Directivity pattern measurement

The studied transducer (single element or transducer array) is also tested in tap water (filtered but non-degassed) at its resonance frequency $\mathrm{F}_{\mathrm{r}}$ (maximum signal received by the hydrophone). This experiment allowed us to determine the far-field directivity pattern of both single element $F_{r s}=448 \mathrm{kHz}$ and transducer array $F_{r a}=476 \mathrm{kHz}$. As illustrated in Fig. 6, the system is composed of a water tank $\left(80 \times 80 \times 60 \mathrm{~cm}^{3}\right)$ in which the emitter (single element or transducer array) and a fabricated polymer polyvinylidenfluoride (PVDF) hydrophone (ISEN, Lille, France) are placed at the far-field distance. Both emitter and receiver are aligned manually in the $\mathrm{x}, \mathrm{y}$ and $\mathrm{z}$ directions, whereas the alignment in the $\varphi$ direction and the rotation $\theta$ of the Hydrophone around the transducer are obtained automatically using a LabVIEW program. Low-Frequency Generator (LFG) is used to excite the emitter (single element or array's central element " 1 ") by applying a sine signal with 40 pulses and $10 \mathrm{~V}_{\mathrm{p}-\mathrm{p}}$ amplitude. The pulse duration $T_{p}=1 / F_{r}$ depends on the signal's frequency, i.e. $T_{p s}=2.23 \mu$ s for the single element (at $F_{r s}=448$ $\mathrm{kHz}$ ) and $\mathrm{T}_{\mathrm{pr}}=2.1 \mu \mathrm{s}$ for the transducer array (at $\mathrm{F}_{\mathrm{ra}}=476 \mathrm{kHz}$ ). The electrical mismatch between the LFG and the emitter are not taken into account (no matching network is utilized). The emitted acoustic signal is then received by the Hydrophone and transmitted to a Filter / Amplifier (Rockland 442 HI / LO Filter), to filter the low and high-frequency noise and amplify the electrical signal before acquisition on the Oscilloscope (hp54600B). Finally, the signal is transmitted to the computer via a GPIB connection, for signal processing and directivity pattern computation.

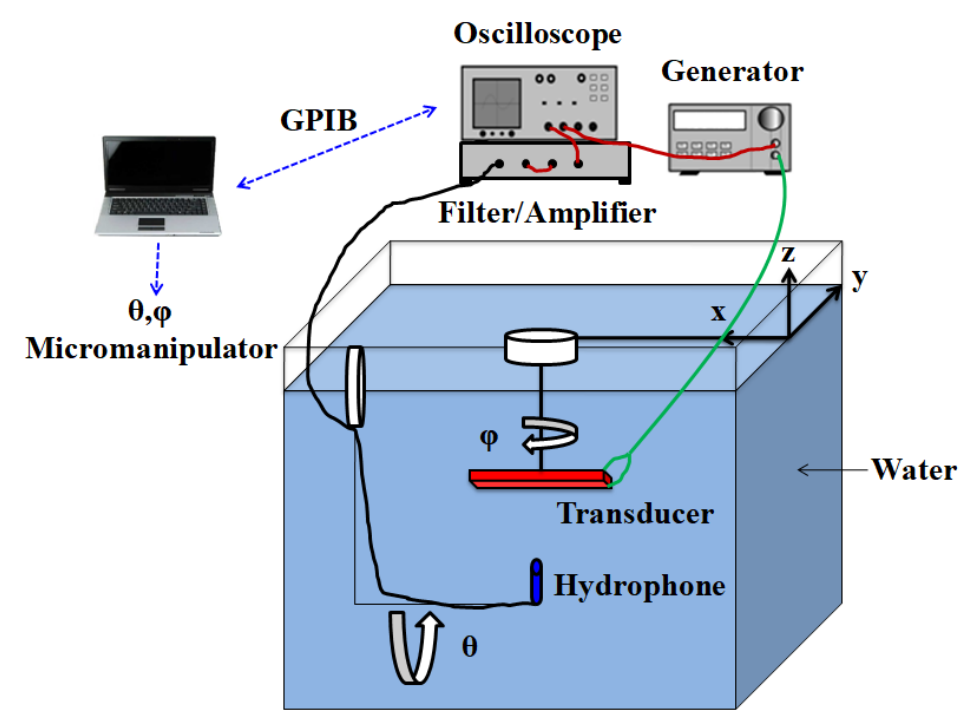

Fig. 6 Schematic description of the directivity pattern measurement

\section{Characterization of Single-element Transducer (Slender Bar)}

\subsection{Impedance measurement}

Firstly, the electrical impedance of a single element which is similar to the transducer array elements (Thickness * Width $*$ Length $=3.3 * 0.7 * 37 \mathrm{~mm}^{3}$ ) is measured between $200 \mathrm{kHz}$ and $1.8 \mathrm{MHz}$. Fig. 7 compares the experimental electrical impedance with which obtained numerically using 2D and 3D Finite Elements Models (FEM) developed in the ATILA code. $2 \mathrm{D}$ and $3 \mathrm{D}$ models are composed respectively of isoparametric quadratic and hexahedral elements respecting the $\lambda / 4$ criterion. Only half of the domain is meshed due to symmetry. As expected, the curves computed using 2D and 3D FEM are similar. In both cases, the thickness vibration modes (fundamental thickness mode and its harmonic) are observed at the same resonance and anti-resonance frequencies. Nevertheless, the curve obtained using 3D FEM shows parasitic modes depending on the element length. Their effect on the element behavior will be discussed later. In addition to this, the numerical results are in good agreement with the experimental one. In both cases, two thickness modes are observed and parasitic length modes are also obtained. The noticed shift in the resonance and anti-resonance frequencies are certainly due to the PZ27 parameters utilized in the numerical models. 


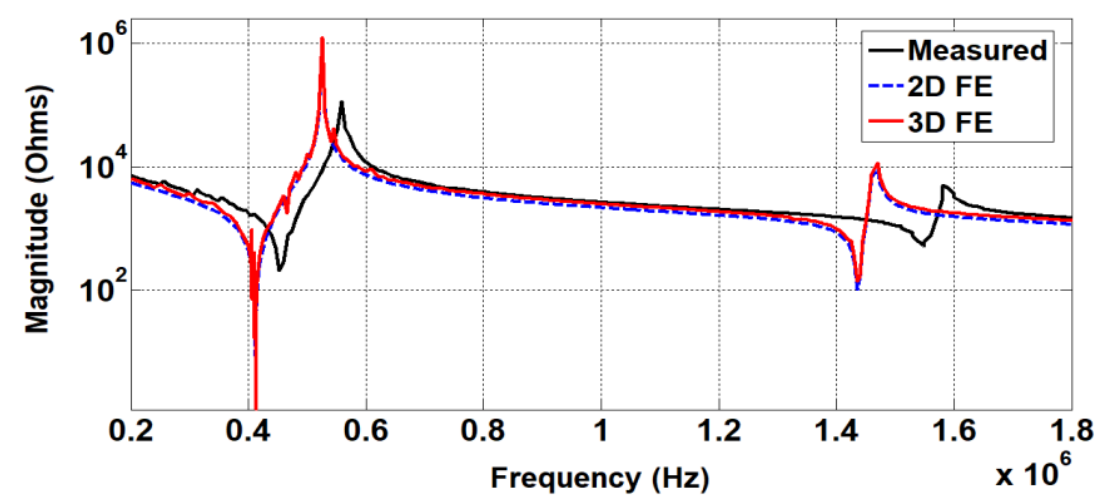

Fig. 7 Electrical impedance magnitude measured and computed using 2D and $3 \mathrm{D} \mathrm{FE}$

\subsection{Displacement measurements}

(1) Displacement in the middle of the element

To determine the mechanical resonant frequency (maximum of displacement) is corresponding to the fundamental thickness mode, the experimental set-up presented previously in Fig. 4 is utilized to measure the displacement in the middle of the piezoelectric element. Fig. 8 shows the normalized displacement magnitude in the frequency domain. As expected the maximum of displacement is obtained at approximately $454 \mathrm{kHz}$ which corresponds also to the electrical resonance frequency (minimum of impedance observed in Fig. 7). The latter is chosen as operating frequency for the next displacement and directivity pattern measurements.

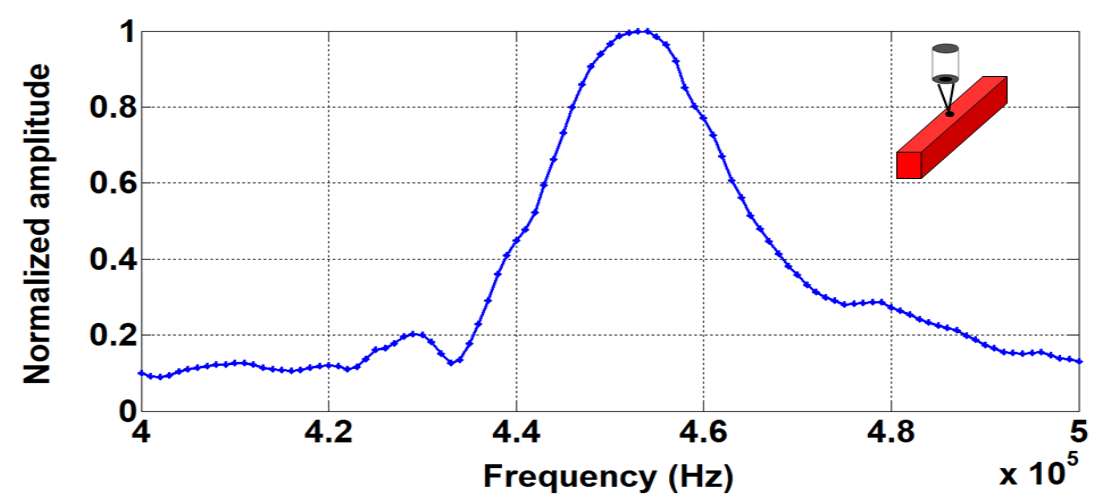

Fig. 8 Normalized displacement amplitude measured in the middle of the element

(2) Displacement along the width (positions $\mathrm{x} 1, \mathrm{x} 2$, and $\mathrm{x} 3$ )

To observe the evolution of the displacement along the width of the slender bar ( $\mathrm{x}$-axis), measurements are realized systematically at different points $\mathrm{x} 1$ (black points), $\mathrm{x} 2$ (blue points) and $\mathrm{x} 3$ (green points) for a given position "y". The results

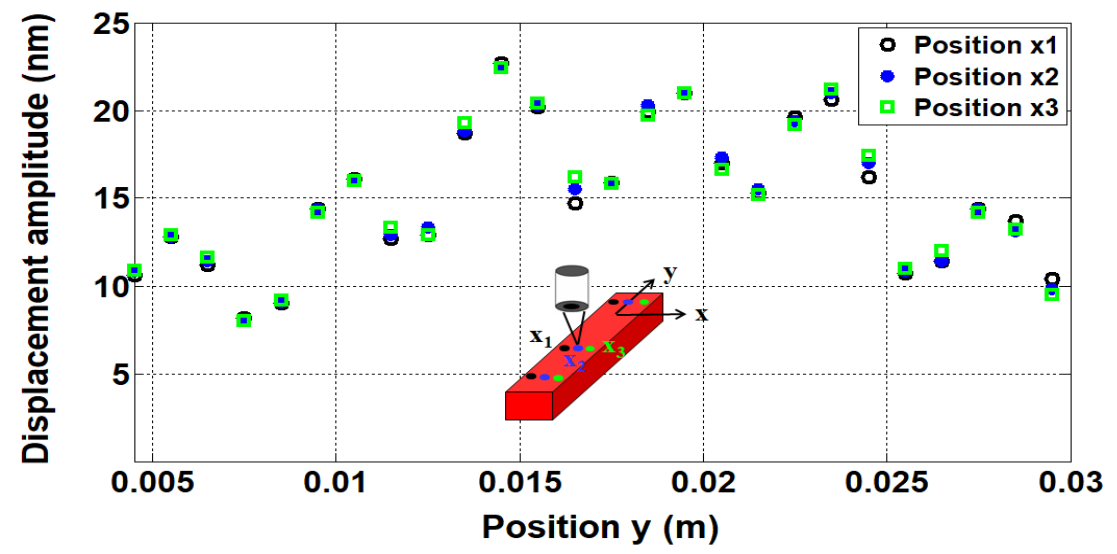

Fig. 9 Displacement amplitude along the width of the element (x-axis) 
obtained are shown in Fig. 9. It is observed that for a fixed position " $y$ " the displacement remains practically the same wherever the position " $x$ " is, i.e. the displacement varies very little along the width of the element. On the other hand, it can be noticed that the displacement is not the same along the element's length (y-axis).

(3) Displacement along the length (y-axis)

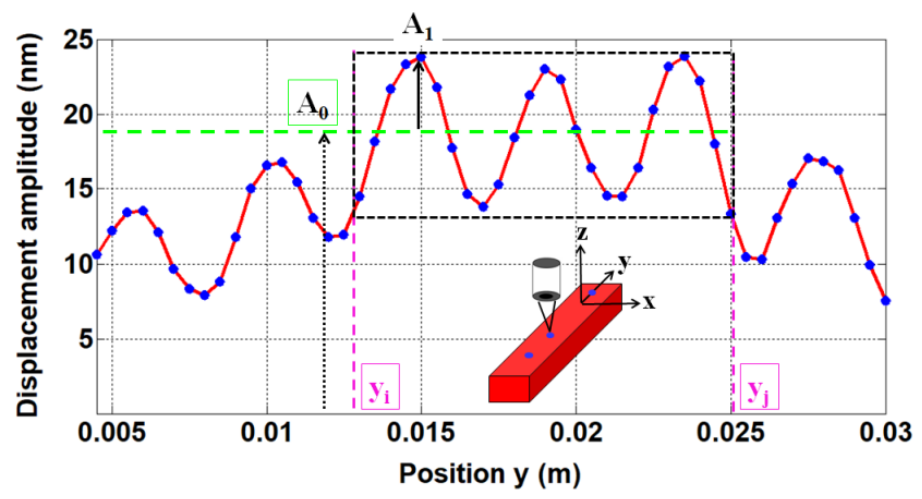

Fig. 10 Displacement amplitude along the piezoelectric element's length (y-axis)

The measurement of the displacement at different points along the transducer's length (y-axis) allowed us to obtain the curve shown in Fig. 10. The experiment is made relatively far from the edges to avoid their parasitic effects (y position varies from $4.5 \mathrm{~mm}$ to $32.5 \mathrm{~mm}$ ). This figure indicates that the displacement measured at the surface of the element is not uniformed. As expected the obtained thickness mode is coupled to a parasitic length mode. In the area far from the transducer's edges, i.e. between $y_{i}$ and $y_{j}$, the displacement's curve is quasi-sinusoidal. Consequently, the approximate expression of the resulting displacement (in the z-direction) can be written as [36]:

$$
u_{z}(y)=A_{0}+A_{1} \cos \left(\frac{2 \pi y}{\lambda_{L}}\right)
$$

where $\mathrm{A}_{0}$ represents the amplitude of the thickness mode (about $18 \mathrm{~nm}$ ). It corresponds to the displacement's average value between yi and yj. $A_{1}$ and $\lambda_{L}$ are respectively the amplitude (about $6 \mathrm{~nm}$ ) and the wavelength (about $4.5 \mathrm{~mm}$ ) of the length mode. The presence of this parasitic mode is due to the transducer's finite length $(37 \mathrm{~mm})$. To evaluate the influence of this undesirable mode and its impact on the $2 \mathrm{D}$ approximation, directivity pattern measurements are carried out in the water.

\subsection{Directivity pattern measurements}

(1) Measurement precautions

To measure the transducer's radiation in water and obtain its directivity pattern with a minimum of errors, some conditions should be respected. First of all, at the emission level, it must be ensured that a suitable number of cycles is chosen to avoid the perturbation of the useful signal by the echoes reflected on the edges of the tank. Furthermore, the number of signals must be relatively important to obtain a quasi-permanent regime (40 cycles in our case). The distance D between the transmitter and the receiver must also be acceptable to satisfy the far-field conditions. This distance must respect the following relation:

$$
\mathrm{D}=\frac{\mathrm{W}^{2}}{\lambda_{\mathrm{w}}}
$$

where $\mathrm{W}$ represents the element's width and $\lambda_{\mathrm{w}}$ the wavelength obtained in water (for medical imaging applications) at the resonant frequency $(448 \mathrm{kHz})$.

As a result, we chose a distance between the transmitter and receiver of $13 \mathrm{~cm}$ to fulfill this condition. Special attention must also be paid to the transducer itself, it is important to realize a shielding around it to prevent the perturbation of the useful 
signal (measured by the hydrophone) by the excitation signal. In our case, a simple layer of aluminum foil connected to the ground (Faraday cage) allowed us to overcome this problem. Fig. 11 shows the signals obtained before and after shielding. It is observed that the parasitic signal has been widely reduced. The last influencing parameter is the acoustic coupling substance introduced between the transducer and the water to ensure optimal transfer of the acoustic signal. In our study, we opted for the use of oil as an acoustic coupling substance which is introduced between the transducer and a protecting plastic film (Mylar) in contact with water.

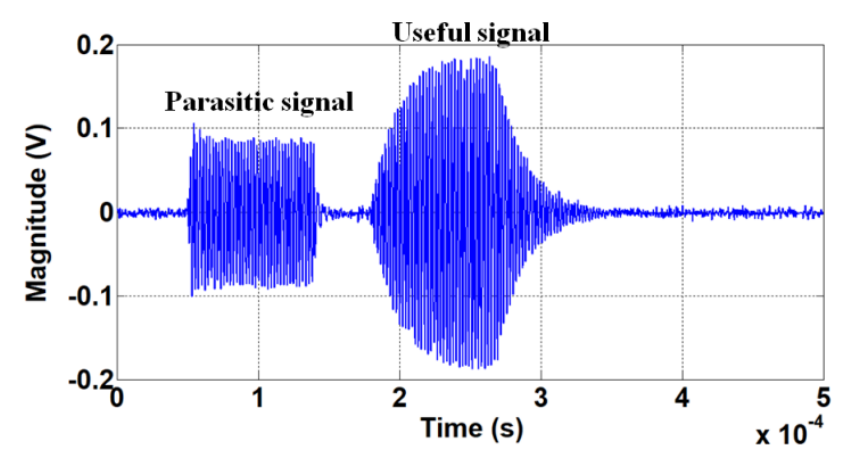

(a) Without shielding

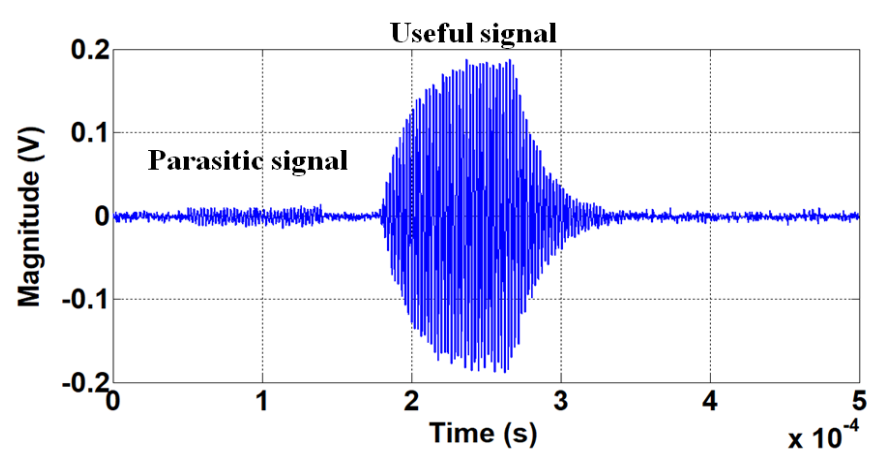

(b) With shielding

Fig. 11 Signal measured using a PVDF hydrophone

\section{(2) Directivity pattern}

The measurement system exposed previously in Fig. 6, which is used to determine the far-field directivity pattern of the single element, for an angle $\theta$ varying from $0^{\circ}$ to $60^{\circ}$ by a step of $2^{\circ}$. The measurement is made at the frequency of $448 \mathrm{kHz}$ corresponding to the maximum amplitude of the signal received by the hydrophone. The result obtained is shown in Fig. 12 in comparison with that determined by analytical and numerical (2D FE) calculations [37]. The analytical directivity is computed using the following relation:

$$
\mathrm{F}_{0}(\theta)=\frac{\sin \left(\frac{\mathrm{kW}}{2} \cos (\theta)\right)}{\frac{\mathrm{kW}}{2} \cos (\theta)} \sin (\theta)
$$

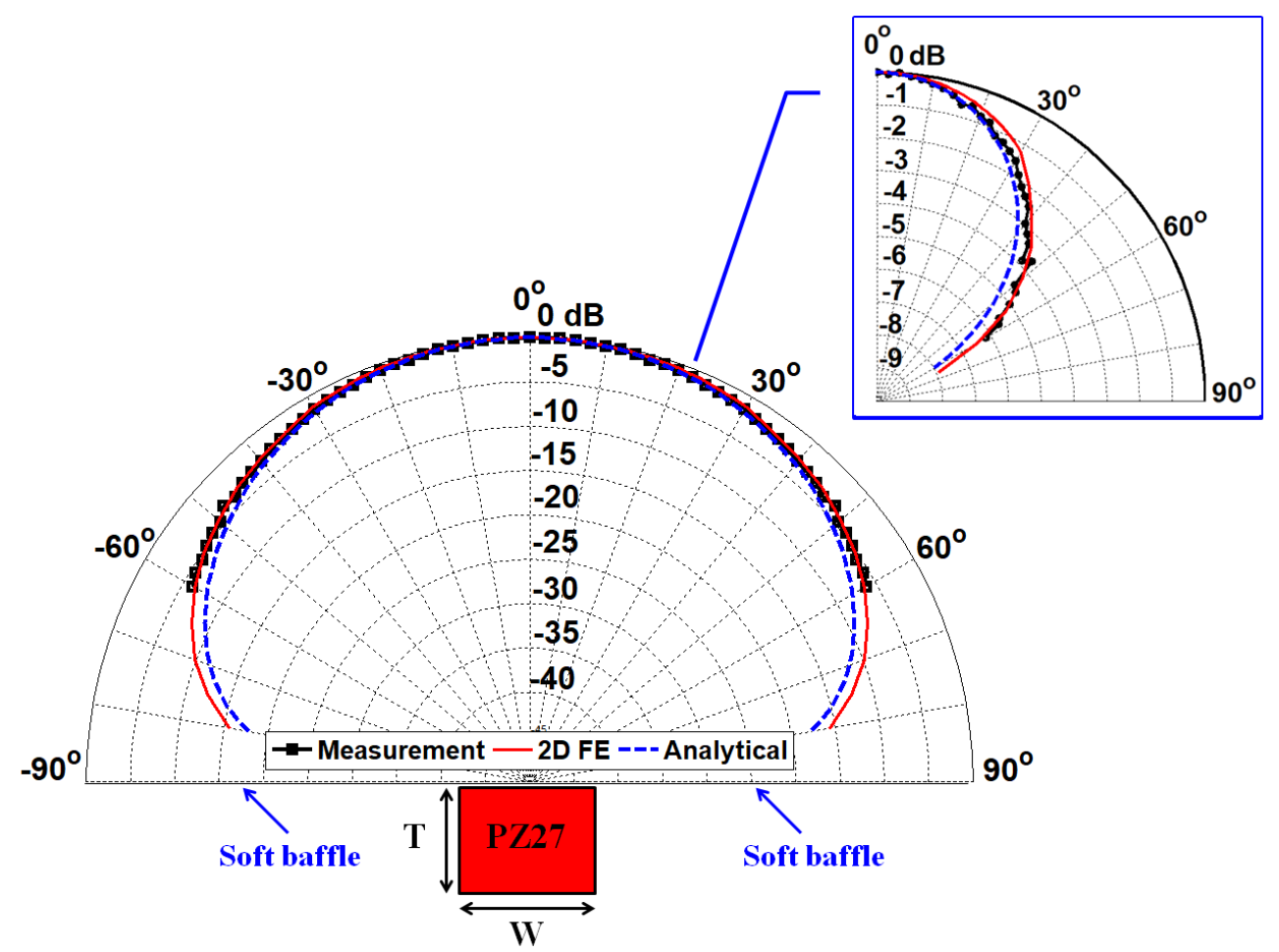

Fig. 12 Directivity pattern measured and computed using analytical and numerical methods 
In this case, the acoustical source i.e. a single piezoelectric element of finite width $\mathrm{W}(0.7 \mathrm{~mm})$ is considered mounted in a soft baffle and the displacement is uniform at its radiating surface. Furthermore, the situation of radiation in far-field is also respected. More details can be found in [38]. From Fig. 12 it is easily observed that the directivities obtained by measurement, analytical and numerical computations are similar, apart from a few differences in amplitude, certainly due to the contribution of the parasitic length mode mentioned previously (Fig. 10). This allows us to conclude that the effect of the parasitic length mode on the single element's directivity pattern can be neglected.

\section{Characterization of the Seven-element Transducer Array}

In this section, the fabricated transducer array (Fig. 3) is fully characterized using the experimental setups described previously in subsection 2.2. Indeed, the electrical impedance, the displacement, and the crosstalk are measured on each element of the transducer array. Moreover, the directivity pattern of the transducer array is measured and compared to the single element one.

\subsection{Electrical impedance measurements}

Electrical impedance measurements are realized on the transducer array elements to check the quality of the fabrication process, i.e. the symmetry of the transducer array. Each element is connected to an impedance analyzer while its neighboring elements are grounded. The results obtained are shown in Fig. 13. After the analysis of Fig. 13(a), two thickness modes are observed, i.e. a fundamental thickness mode around the frequency $F_{r}=500 \mathrm{kHz}$ and its harmonic around the frequency $F_{r}=$ $1.55 \mathrm{MHz}$.

From Fig. 13 (b), it can be seen that the impedance curves of the elements " 2 " and "-2", "3" and "-3", "4" and "-4" are similar (less than $1 \%$ of difference), which indicates a good symmetry and validates the fabrication process. From the same figure, several parasitic vibrations are observed around the resonant frequency (minimum of impedance) making it difficult to distinguish contrary to the case of the single element (Fig. 7). These parasitic vibrations correspond to the undesired interactions between the array elements (crosstalk), which change the behavior of the individual elements.

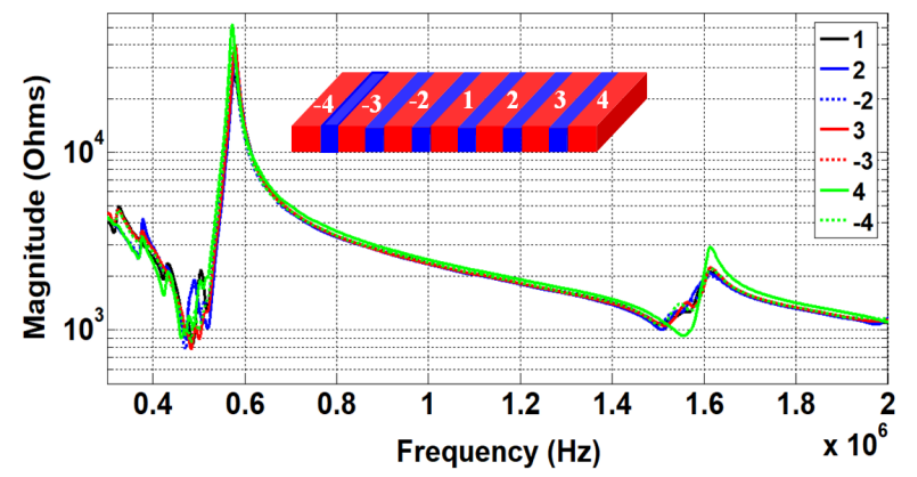

(a) Fundamental thickness resonant mode and its harmonic

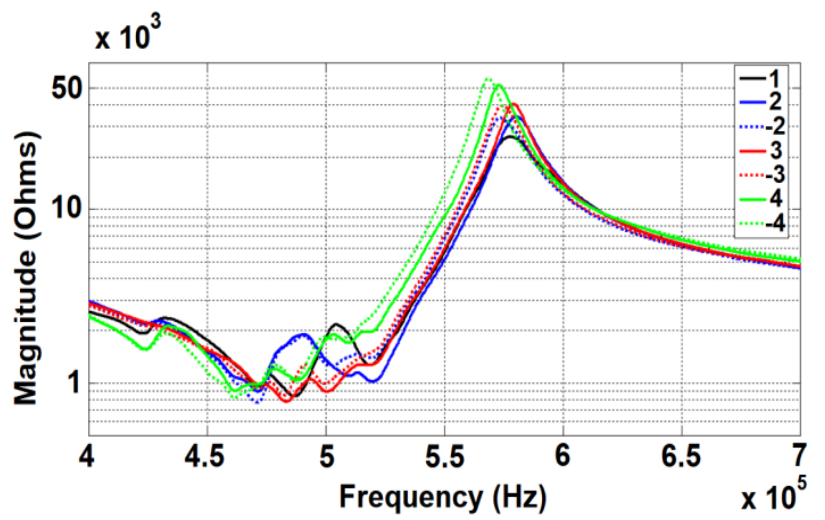

(b) Fundamental thickness resonant mode

Fig. 13 Electrical impedance magnitude measured on the transducer array elements “1”, “2”, “-2”, “3”, “-3”, “4” and “-4”

\subsection{Displacement measurements}

The experimental set-up presented in Fig. 4 is utilized to measure the displacement at the surface of the array elements. Measurements are first realized in the middle of the elements to determine their resonant frequency (maximum of displacement). In this case, each element is excited by a sinusoidal signal having a magnitude $10 \mathrm{~V}$ and a frequency varying from $400 \mathrm{kHz}$ to $600 \mathrm{kHz}$ while its neighboring elements are grounded. The experimental normalized displacement amplitudes are given in Fig. 14. The latter indicates the presence of strong crosstalk between elements, i.e. several displacement maximums are observed in the frequency band $450 \mathrm{kHz}-550 \mathrm{kHz}$ which makes the result very different from an element to the 

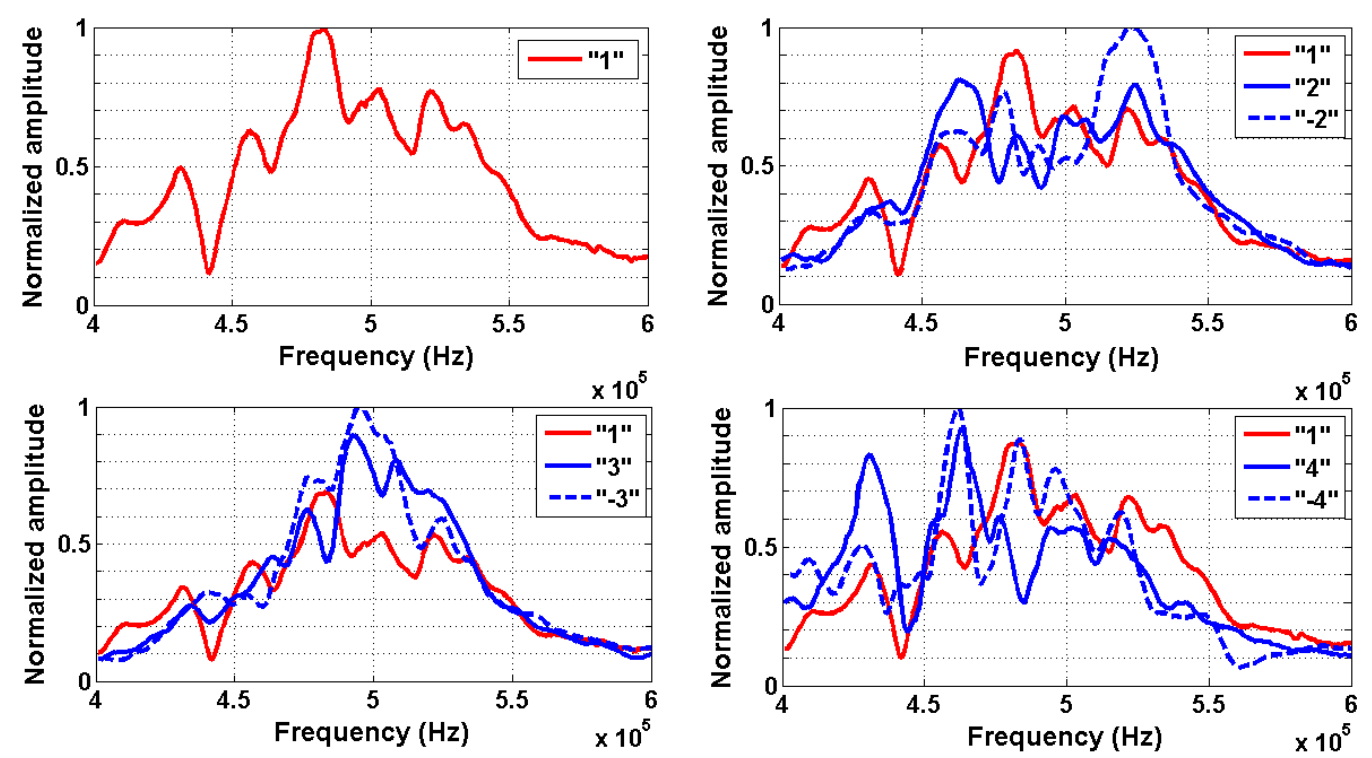

Fig. 14 Normalized displacement amplitude obtained on the transducer array elements

other. Nevertheless, as expected the curves of the element " 2 " and "-2", "3" and "-3", "4" and "-4" are relatively similar due to the array symmetry. In the case of the central element " 1 ”, a maximum of displacement is observed at the frequency $481 \mathrm{kHz}$, which is considered as the operating frequency for the rest of experiments.

To observe the mechanical behavior of the transducer array (structure vibration) when the central element " 1 " is excited at the resonance frequency $481 \mathrm{kHz}$ and its neighboring elements are grounded, displacement measurements are realized at the radiating surface of the array. Fig. 15(a) shows the displacement obtained at different points of the surface, i.e. 41 points along the length and 27 along the width of the transducer array. It is observed from this figure that the driven element " 1 " vibrates mainly in thickness mode but the displacement is not completely the same in all points (the displacement is not uniform), due to the parasitic length mode discussed previously in subsection 3.2. Furthermore, the presence of parasitic displacements on the passive elements " $2,-2$ ", “ $3,-3$ ” and “4, -4 ” indicates the importance of the interactions between the array elements (crosstalk). In addition to this, due to the limited number of elements in the transducer array (seven elements), the parasitic displacement measured on the third elements " 4 " and " -4 " is significant compared to the one obtained on the elements " $2,-2$ " and " 3 , -3 ". In other words, the edge effects are not negligible. To quantify the crosstalk effects, the displacements measured at different points $\mathrm{P}_{\mathrm{i}}(\mathrm{i}=1, \ldots 41)$ along the length of the excited element " 1 " and its neighboring elements " 2 ", " 3 " and " 4 " are compared in Fig. 15(b). As said previously, a dominant thickness mode is obtained for the element "1" and significant parasitic displacements are observed on its passive neighboring elements, i.e. about $25 \%$ of the displacement amplitude on the element " 2 " and " 3 " and $40 \%$ on the element " 4 " due to the edge effects.

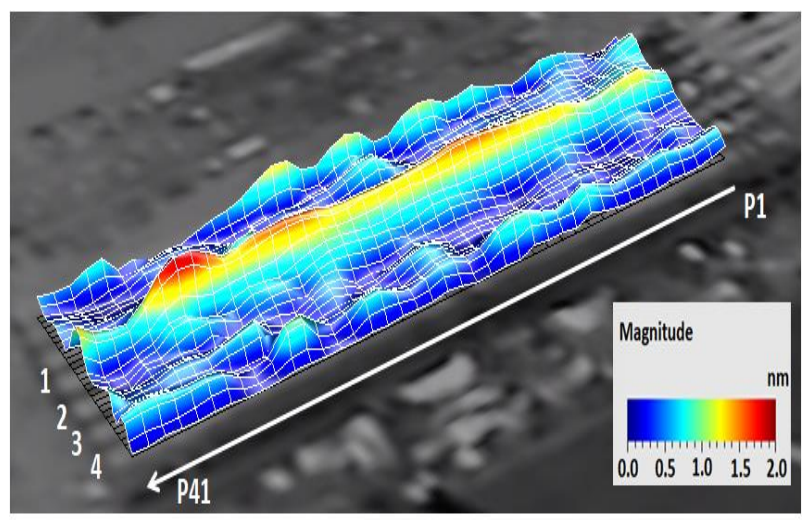

(a) Displacement at the surface of the transducer array

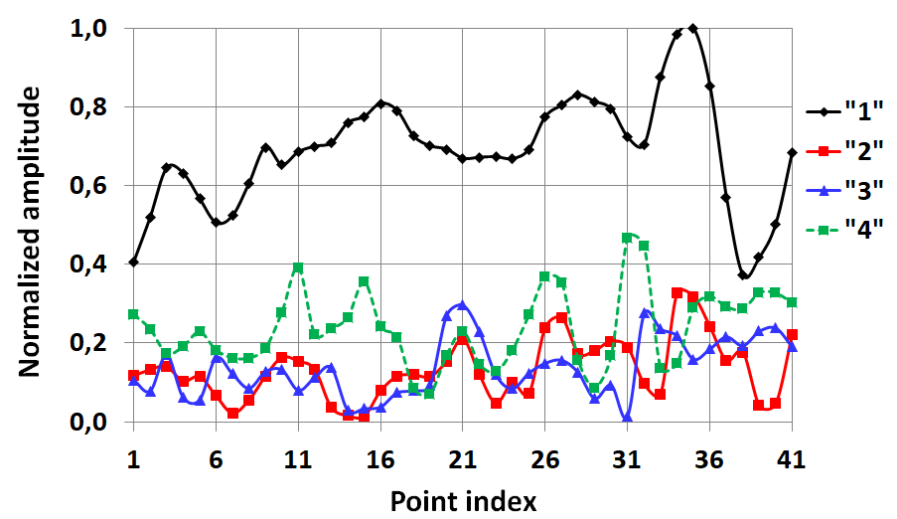

(b) Normalized displacement amplitude obtained on the elements "1", "2", "3" and "4" (points indexed from P1 to P41)

Fig. 15 Displacement measured at the surface of the array when the element " 1 " is driven at its resonant frequency $481 \mathrm{kHz}$ 
To observe the evolution of the displacement along the width of each element of the transducer array, measurements are also realized in three points $\mathrm{x} 1, \mathrm{x} 2$, and $\mathrm{x} 3$ situated at the position $\mathrm{y}_{0}=\mathrm{L} / 3$ (L element length) to avoid edge effects. The results obtained in the frequency domain are plotted in Fig. 16. It is seen that the displacement remains practically the same wherever the position " $x$ " is, i.e. the displacement varies very little along the width of the element. Nevertheless, significant differences can be observed for specific frequencies e.g. $513 \mathrm{kHz}$. In this case, differences about 20\%, 25\% and 10\% are obtained for the elements "2", “3", "4" respectively. In addition to this, it can be noticed that the displacement curves are a little different from that obtained previously in the middle of the array elements i.e. $y=$ L/2 (Fig. 14). However, for the central element " 1 " a maximum of displacement is obtained at the frequency $481 \mathrm{kHz}$ as in the case of the measurements are done in the middle of the elements.
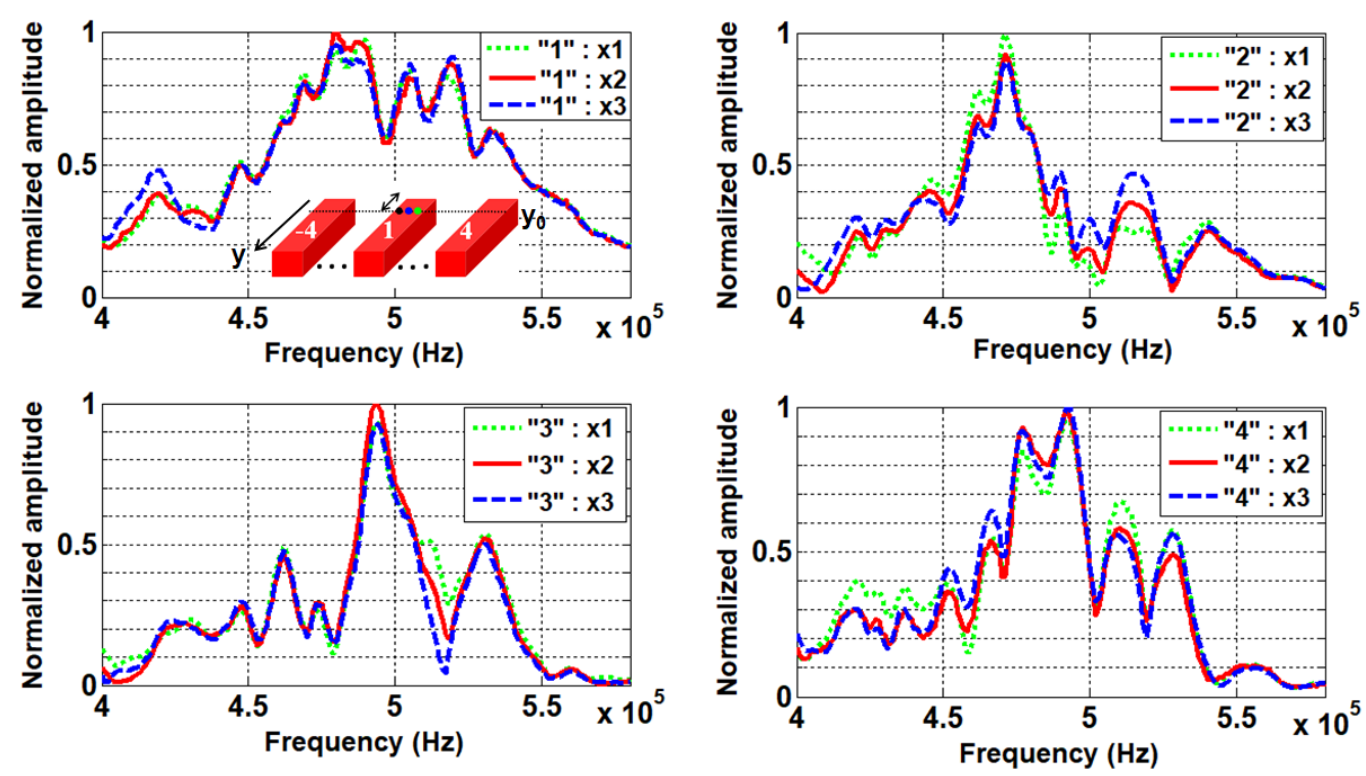

Fig. 16 Displacement amplitude measured along the width of the elements (points $\mathrm{x} 1$, $\mathrm{x} 2, \mathrm{x} 3$ ) at the frequency $481 \mathrm{kHz}$

\subsection{Directivity pattern measurements}

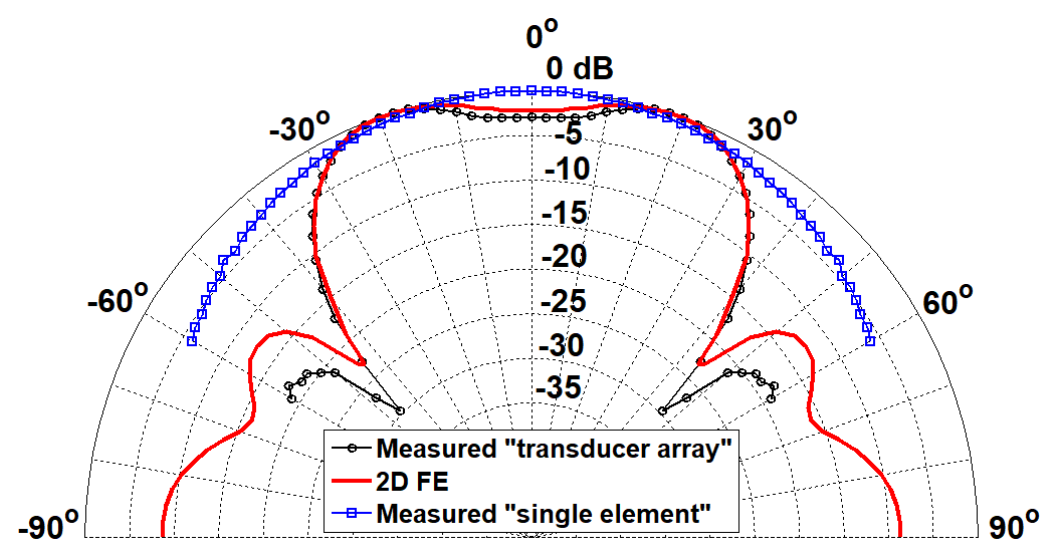

Fig. 17 Transducer array's experimental and numerical directivity patterns compared to the single element one

The directivity pattern of the seven-element transducer array is measured when the central element " 1 " is driven at the frequency $481 \mathrm{kHz}$ and its neighboring elements are grounded. Measurements are carried out using the experimental set-up described previously in Fig. 6 , between $0^{\circ}$ and $60^{\circ}$ at intervals of $2^{\circ}$. The experimental results are then compared to those obtained numerically using 2D Finite Elements Method (Fig. 17) [27]. According to Fig. 17 it is clear that the experimental directivity pattern is similar to that predicted numerically (2D FE). In both cases, the curves present a main lobe in the directions $\pm 20^{\circ}$ and other side lobes in the directions $\pm 55^{\circ}$. Moreover, the experimental directivity pattern of a single element, 
which can be considered as the ideal case, has also been added to Fig. 17. Regarding the results, it is clear that the directivity pattern of the transducer array is strongly disturbed by the interactions between the array elements (crosstalk). Some differences between experimental and numerical results can be noted because the fabricated device is not perfectly matched to the model structure in terms of symmetry and material properties.

\subsection{Crosstalk measurements}

In the previous electrical and mechanical experiments (electrical impedance, displacement and directivity pattern measurements) strong interactions are observed between the transducer array elements. The objective of this subsection is thus to evaluate the crosstalk level in the fabricated prototype using the relation (1). The measurements are realized utilizing the experimental set-up shown in Fig. 5. In this case, the central element " 1 " is excited in transient domain by a three-cycle sinusoidal signal at the frequency of $500 \mathrm{kHz}$ with a magnitude of $10 \mathrm{~V}$. The parasitic signals measured on the neighboring elements "2", “3”, "4" and the corresponding crosstalk levels are displayed in Fig. 18. This latter shows clearly the presence of significant parasitic signals on these passive elements. Consequently, high levels of crosstalk are obtained i.e. about $-7.3 \mathrm{~dB}$, $-11 \mathrm{~dB}$ and $-12 \mathrm{~dB}$ on the first, second and third neighboring elements respectively.

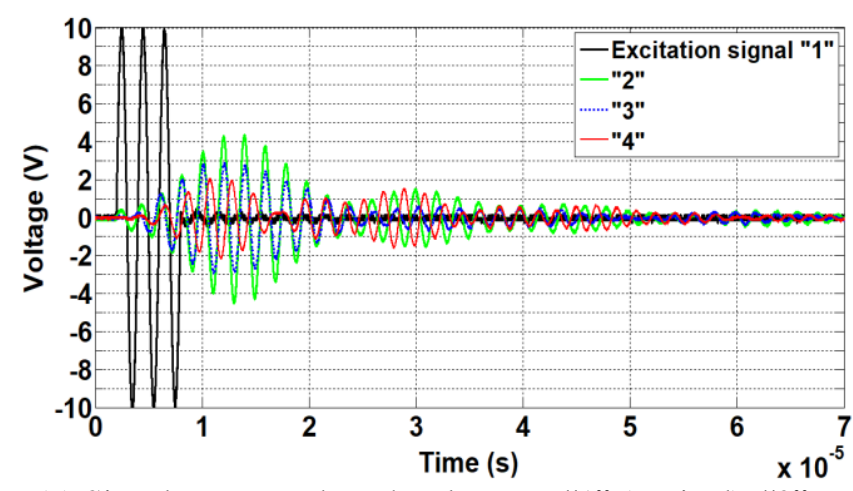

(a) Signals measured on the elements "1" (excited), "2", " 3 " and " 4 "

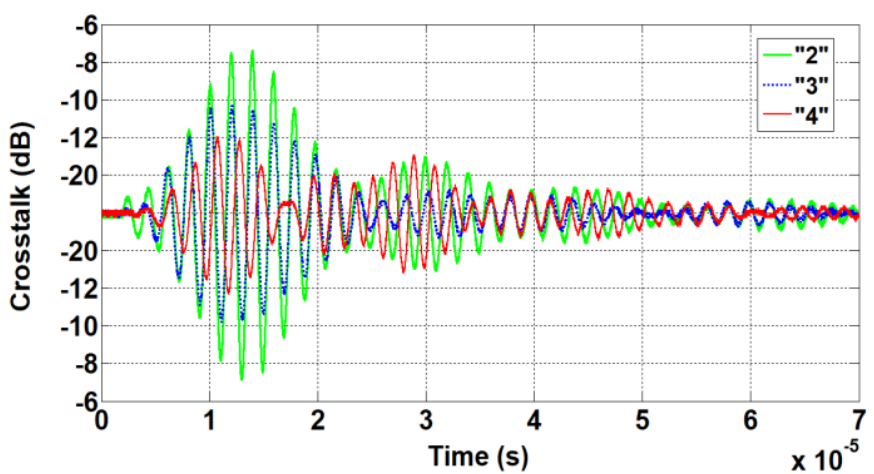

(b) Crosstalk signals measured on the elements " 2 ", " 3 " and " 4 "

Fig. 18 Excitation and crosstalk signals measured on the elements "1", "2", “3” and "4"

\section{Conclusions}

In this paper, a fabricated piezoelectric transducer array is characterized experimentally by electrical and mechanical measurements. To better understand the transducer array's behavior and to facilitate the interpretation of the obtained results, experiments are first performed in the case of a single piezoelectric element (slender bar) considered as a reference case. The manufactured seven-element transducer array is then characterized in one hand by electrical impedance measurements to check its symmetry and validate the fabrication process. On the other hand, displacement measurements are realized at the transducer's radiating surface to determine its thickness resonant frequency considered as the operating frequency and to observe its mechanical behavior. As expected, the results have shown that the structure vibrates mainly in thickness mode, but the displacement is not uniform along the length of the elements due to the contribution of the parasitic length mode. Furthermore, important parasitic displacements are obtained on the neighboring passive elements because of the crosstalk phenomenon. Consequently, high levels of crosstalk are measured, i.e. about $-7.3 \mathrm{~dB},-11 \mathrm{~dB}$, and $-12 \mathrm{~dB}$, on the first, the second and the third neighboring elements respectively. Finally, the effects of the undesirable displacements (crosstalk) on the array's radiation in water, is observed in the obtained directivity pattern in comparison with that of the reference case (single element).

\section{Conflicts of Interest}

The authors declare no conflict of interest. 


\section{Acknowledgement}

The author is pleased to acknowledge the support of the laboratories LMCPA-Maubeuge, IEMN-DOAE-Valenciennes and the acoustic laboratory of ISEN-Lille.

\section{References}

[1] J. Lee, J. Y. Moon, and J. Chang, "A $35 \mathrm{MHz} / 105 \mathrm{MHz}$ dual-element focused transducer for intravascular ultrasound tissue imaging using the third harmonic," Sensors, vol. 18, no.7, pp. 2290, July 2018.

[2] R. H. Silverman, "Focused ultrasound in ophthalmology," Clinical Ophthalmology, vol. 10, pp. 1865-1875, September 2016.

[3] S. Ovel, Sonography exam review: physics, abdomen, obstetrics and gynecology, 2nd ed. Elsevier Health Sciences, 2013.

[4] J. Y. Zhang, W. J. Xu, J. Carlier, X. M. Ji, S. Queste, B. Nongaillard, and Y. P. Huang, "Numerical and experimental investigation of kerf depth effect on high-frequency phased array transducer," Ultrasonics, vol. 52, no. 2, pp. 223-229, February 2012.

[5] W. Wang, S. W. Or, Q. Yue, Y. Zhang, J. Jiao, B. Ren, D. Lin, C. M. Leung, X. Zhao, and H. Luo, "Cylindrically shaped ultrasonic linear array fabricated using PIMNT/epoxy 1-3 piezoelectric composite," Sensors and Actuators A: Physical, vol. 192, pp. 69-75, 2013.

[6] A. Bezanson, R. Adamson, and J. A. Brown, "Fabrication and performance of a miniaturized 64-element high-frequency endoscopic phased array," IEEE Transactions on Ultrasonics, Ferroelectrics, and Frequency Control, vol. 61, no. 1, pp. 33-43, January 2014.

[7] R. Chen, N. E. Cabrera-Munoz, K. H. Lam, H. S. Hsu, F. Zheng, Q. Zhou, and K. K. Shung, "PMN-PT single-crystal high-frequency kerfless phased array," IEEE Transactions on Ultrasonics, Ferroelectrics, and Frequency Control, vol. 61, no. 6, pp. 1033-1041, June 2014.

[8] A. Abrar, D. Zhang, B. Su, T. W. Button, K. J. Kirk, and S. Cochran, "1-3 connectivity piezoelectric ceramic-polymer composite transducers made with viscous polymer processing for high frequency ultrasound," Ultrasonics, vol. 42, no. 1-9, pp. 479-484, April 2004.

[9] J. M. Cannata, J. A. Williams, Q. Zhou, T. A. Ritter, and K. K. Shung, "Development of a 35-MHz piezo-composite ultrasound array for medical imaging," IEEE Transactions on Ultrasonics, Ferroelectrics, and Frequency Control, vol. 53, no. 1, pp. 224-236, January 2006.

[10] H. R. Chabok, J. M. Cannata, H. H. Kim, J. Williams, J. Park, and K. K. Shung, “A high-frequency annular-array transducer using an interdigital bonded 1-3 composite," IEEE Transactions on Ultrasonics, Ferroelectrics, and Frequency Control, vol. 58, no. 1, pp. 206-214, January 2011.

[11] Q. Zhang, P. A. Lewin, and P. E. Bloomfield, "Variable-frequency multilayer PVDF transducers for ultrasound imaging," Proc. International Society for Optics and Photonics, Medical Imaging 1997: Ultrasonic transducer engineering, April 1997, vol. 3037, pp. 2-12.

[12] K. Brenner, A. S. Ergun, K. Firouzi, M. F. Rasmussen, Q. Stedman, and B. Khuri-Yakub, "Advances in capacitive micromachined ultrasonic transducers," Micromachines, vol. 10, no. 2, pp. 152, February 2019.

[13] B. C. Lee, A. Nikoozadeh, K. K. Park, and B. T. Khuri-Yakub, "High-efficiency output pressure performance using capacitive micromachined ultrasonic transducers with substrate-embedded springs," Sensors, vol. 18, no. 8, pp. E2520, August 2018.

[14] J. H. Jang, C. Chang, M. F. Rasmussen, K. Brenner, and Q. Stedman, "Dual-mode capacitive micromachined ultrasonic transducer arrays for high intensity focused ultrasound and imaging," The Journal of the Acoustical Society of America, vol. 144, no. 3, pp. 1698-1698, September 2018.

[15] A. Bybi, O. Mouhat, M. Garoum, H. Drissi, and S. Grondel, "One-dimensional equivalent circuit for ultrasonic transducer arrays," Applied Acoustics, vol. 156, pp. 246-257, 2019.

[16] S. Pyo and Y. Roh, "Analysis of the crosstalk in an underwater planar array transducer by the equivalent circuit method," Japanese Journal of Applied Physics, vol. 56, no. 7S1, pp. 07JG01-1-07JG01-6, June 2017.

[17] C. Ishihara, T. Ikedaa, and H. Masuzawaa, "Higher-frame-rate ultrasound imaging with reduced cross-talk by combining a synthetic aperture and spatial coded excitation," Proc. International Society for Optics and Photonics, Medical Imaging, Ultrasonic Imaging and Tomography, April 2016, vol. 9790, pp. 97901Z-1-97901Z-7.

[18] L. Tong, Q. He, A. Ortega, A. Ramalli, P. Tortoli, J. Luo, and J. D'hooge, "Coded excitation for crosstalk suppression in multi-line transmit beamforming: simulation study and experimental validation," Applied Sciences, vol. 9, no. 3, pp. 486, January 2019.

[19] F. P. Branca, F. Bini, F. Marinozzi, and A. Grandoni, "Optimum choice of acoustic properties of filling materials using optical measurement," IEEE Ultrasonics Symposium (IUS), August, 2004, vol. 3, pp. 1663-1665. 
[20] W. Lee and Y. Roh, "Optimal design of a piezoelectric 2D array transducer to minimize the cross talk between active elements," IEEE Ultrasonics Symposium (IUS), September, 2009, pp. 2738-2741.

[21] H. J. Fang, Y. Chen C. M. Wong, W. B. Qiu, H. L. W. Chan, J. Y. Dai, Q. Li, and Q. F. Yan, "Anodic aluminum oxide-epoxy composite acoustic matching layers for ultrasonic transducer application," Ultrasonics, vol. 70, pp. 29-33, August, 2016.

[22] M. H. Amini, T. W. Coyle and, T. Sinclair, "Porous ceramics as backing element for high-temperature transducers," IEEE Transactions on Ultrasonics, Ferroelectrics, and Frequency Control, vol. 62, no. 2, pp. 360-372, February, 2015.

[23] S. M. Ji, J. H. Sung, C. Y. Park, and J. S. Jeong, "Phase-canceled backing structure for lightweight ultrasonic transducer," Sensors and Actuators A: Physical, vol. 260, pp. 161-168, 2017.

[24] M. Celmer, K. J. Opielinski, and M. Dopierała, "Structural model of standard ultrasonic transducer array developed for FEM analysis of mechanical crosstalk," Ultrasonics, vol. 83, pp. 114-119, February, 2018.

[25] K. J. Opielinski, M. Celmer, and R. Bolejko, "Crosstalk Effect in Medical Ultrasound Tomography Imaging," Joint Conference - Acoustics, September 2018, pp. 1-6.

[26] A. Bybi, S. Grondel, J. Assaad, A. C. Hladky -Hennion, C. Granger, and M. Rguiti, "Reducing crosstalk in array structures by controlling the excitation voltage of individual elements: a feasibility study,” Ultrasonics, vol. 53, no. 6, pp. 1135-1140, August 2013.

[27] A. Bybi, C. Granger, S. Grondel, A. C. Hladky -Hennion, and J. Assaad, "Electrical method for crosstalk cancellation in transducer arrays," NDT E International, vol. 62, pp. 115-121, March 2014.

[28] S. Zhou and J. A. Hossack, "Reducing inter-element acoustic crosstalk in capacitive micromachined ultrasound transducers," IEEE Transactions on Ultrasonics, Ferroelectrics, and Frequency Control, vol. 54, no. 6, pp. 1217-1228, June 2007.

[29] A. Bybi, S. Grondel, A. Mzerd, C. Granger, M. Garoum, and J. Assaad, "Investigation of cross-coupling in piezoelectric transducer arrays and correction," International Journal of Engineering and Technology Innovation, vol. 9, no. 4, pp. 287-301, October 2019.

[30] K. C. T. Nguyen, L. H. Le, M. D. Sacchi, L. Q. Huynh, and E. Lou, "Adaptive noise cancellation in the intercept times-slowness domain for eliminating ultrasonic crosstalk in a transducer array," Proc. 5th International Conference on Biomedical Engineering in Vietnam, Springer, August 2015, vol. 46, pp. 32-35.

[31] D. M. Mills and S. W. Smith, "Multi-layered PZT/polymer composites to increase signal-to-noise ratio and resolution for medical ultrasound transducers. II. Thick film technology,” IEEE Transactions on Ultrasonics, Ferroelectrics, and Frequency Control, vol. 49, no. 7, pp. 1005-1014, August 2002.

[32] T. Lilliehorn and S. Johansson, "Fabrication of multilayer 2D ultrasonic transducer micoarrays by green machining," Journal of Micromechanics and Microengineering, vol. 14, no. 5, pp. 702-709, March 2004.

[33] D. M. Mills and S. W. Smith, "Multi-layered PZT/polymer composites to increase signal-to-noise ratio and resolution for medical ultrasound transducers," IEEE Transactions on Ultrasonics, Ferroelectrics, and Frequency Control, vol. 46, no. 4, pp. 961-971, July 1999.

[34] P. Anastasiadis, A. Mohammadabadi, M. J. Fishman, J. A. Smith, B. A. Nguyen, D. S. Hersh, and V. Frenkel, "Design, characterization and evaluation of a laser-guided focused ultrasound system for preclinical investigations," Biomedical Engineering OnLine, vol. 18, no. 1, pp. 36, March 2019.

[35] D. S. Hersh, P. Anastasiadis, A. Mohammadabadi, B. A. Nguyen, S. Guo, J. A. Winkles, A. J. Kim, R. Gullapalli, A. Keller, V. Frenkel, and G. F. Woodworth, "MR-guided transcranial focused ultrasound safely enhances interstitial dispersion of large polymeric nanoparticles in the living brain," PloS one, vol. 13, no. 2, pp. e0192240, Febreuary 2018.

[36] J. Assaad, J. N. Decarpigny, C. Bruneel, and B. Nongaillard, "Electromechanical coupling coefficients and far-field radiation patterns of lithium niobate bars (Y-cut) used in high-frequency acoustical imaging and nondestructive testing," The Journal of the Acoustical Society of America, vol. 94, no. 5, pp. 2969-2978, November 1993.

[37] N. El Atlas, A. Bybi, H. Drissi, and A. C. Hladky -Hennion, "Finite element modeling of a piezoelectric slender bar transducer equipped with a multilayer backing for medical imaging applications," Proc. 3rd International Conference on Electrical and Information Technologies (ICEIT), November 2017.

[38] J. Assaad, J. N. Decarpigny, C. Bruneel, R. Bossut, and B. Hamonic, "Application of the finite element method to two-dimensional radiation problems," The Journal of the Acoustical Society of America, vol. 94, no. 1, pp. 562-573, July 1993.

Copyright $\odot$ by the authors. Licensee TAETI, Taiwan. This article is an open access article distributed under the terms and conditions of the Creative Commons Attribution (CC BY-NC) license (https://creativecommons.org/licenses/by-nc/4.0/). 